2.

Derecho penal 



\title{
EL DELITO DE NEGATIVA INJUSTIFICADA DE UN CONDUCTOR A SOMETERSE A LOS EXÁMENES DE DETECCIÓN DE ALCOHOL O SUSTANCIAS ESTUPEFACIENTES O PSICOTRÓPICAS
}

[The Offense of Unjustified Refusal by a Driver to Undergo Alcohol or Narcotic or Psychotropic Drug Testing]

\author{
Diego Falcone Salas* \\ Pontificia Universidad Católica de Valparaíso, Chile
}

\begin{abstract}
RESUMEN
La reciente entrada en vigencia de la Ley $\mathrm{N}^{\circ} 20.770$ supuso varias modificaciones al derecho penal del Tránsito. Se aborda aquí el estudio del nuevo delito consistente en la negativa injustificada de un conductor a someterse a las pruebas o exámenes de detección de alcohol o sustancias estupefacientes o psicotrópicas, atendiendo fundamentalmente a su estructura típica objetiva y subjetiva.
\end{abstract}

\section{Palabras clave}

Ley $\mathrm{N}^{\circ} 20.770$ - Delito de negativa a pruebas o exámenes de alcoholemia Seguridad vial.

\section{ABSTRACT}

Act No. 20.770, which recently came into effect, entailed several changes to the Traffic Criminal Legislation. This article addresses the study of a new offense consisting in the unjustified refusal by a driver to undergo alcohol or narcotic or psychotropic drug testing, with a main focus on the typical objective and subjective structure.

\section{KEYWORDS}

Act No. 20.770 - Offense of refusal to undergo alcohol testing - Road Traffic Safety.

RECIBIDO el 4 de mayo y ACEPTADO el 20 de julio de 2015

* Máster en derecho penal y ciencias penales. Profesor de la Escuela de Derecho de la Pontificia Universidad Católica de Valparaíso. Dirección postal: Avenida Brasil 2950, Valparaíso, Chile. Correo electrónico: diegofalcone@yahoo.com 


\section{INTRODUCCIÓN**}

El día 16 de septiembre de 2014 fue publicada y entró en vigor la Ley № 20.770, cuyo epígrafe expresa: Modifica la Ley del Tránsito en lo que se refiere al delito de manejo en estado de ebriedad, causando lesiones graves, gravisimas o, con resultado de muerte. A pesar que la intención primitiva de legislar en la materia, como resulta de público conocimiento, tuvo por cometido el punir de forma más severa los comportamientos que el epígrafe reproducido indica, el resultado final de esta labor es de más amplios márgenes, estableciendo modificaciones que no sólo apuntan a la finalidad señalada, sino también a otras tantas.

Una de ellas es la creación de un nuevo delito, consistente en la negativa del conductor a someterse a las pruebas respiratorias u otros exámenes científicos destinados a establecer la presencia de alcohol o de sustancias estupefacientes o psicotrópicas.

Este trabajo tiene por objeto realizar un análisis de la figura penal, de reciente establecimiento, poniendo acento en el bien jurídico protegido y en las estructuras típicas establecidas en el artículo 195 bis LT, en sus aspectos objetivo y subjetivo. Para una mejor comprensión, se hace un esbozo del desarrollo histórico normativo y, al final, se formulan conclusiones que contienen un juicio crítico respecto de la modificación legal.

\section{BREVE REMISIÓN AL TRATAMIENTO LEGAL DE LAS PRUEBAS}

DE DETECCIÓN DE ALCOHOL O DROGAS EN MATERIA DE TRÁNSITO

Para comprender mejor la regulación actual en materia de pruebas y exámenes de detección de alcohol o drogas, que incide directamente en la tipicidad del delito que nos ocupa, es necesario hacer un somero repaso de la evolución legislativa.

En términos generales, hay que señalar que en Chile, dicha regulación se ha producido por dos vertientes distintas, que han convergido, finalmente, en la legislación actual. Nos referimos, por una parte, a la efectuada a propósito del alcohol y, por otra, a la vinculada con la normativa del tránsito.

1. Prueba respiratoria y examen de alcoholemia en la Ley $N^{\circ} 17.105$.

La Ley $N^{\circ}$ 17.105: Sobre alcoholes, bebidas alcohólicas y vinagres ${ }^{1}$, en su artículo 121, tipificaba el delito de conducción en estado de ebriedad. En

** En este trabajo, la abreviatura LT. Mienta la Ley $\mathrm{N}^{\circ} 18.290$ del Tránsito (o su texto refundido, coordinado y sistematizado por Decreto con fuerza de ley $\mathrm{N}^{\circ} 1$, publicado en D.O. de 29 de octubre de 2009).

${ }^{1}$ Publicada en D.O. de 14 de abril de 1969. 
el artículo 120, facultaba a las autoridades policiales para someter a una prueba respiratoria, destinada a determinar la presencia de alcohol en la sangre o en el organismo, a toda persona que condujera o se aprestara a conducir un vehículo en un lugar público. Partiendo de la base que el sujeto se sometiera a dicha prueba, y que ella resultara positiva, se presentaban dos alternativas: i) Que el sujeto sólo estuviese bajo la influencia del alcohol lo que, a la época, era penalmente irrelevante; ii) Que el sujeto estuviese en estado de ebriedad lo que implicaba, por lo pronto, que debía ser detenido por el delito respectivo. Sólo en esta última situación, los funcionarios de Carabineros o de Investigaciones debían tomar las medidas inmediatas para someter al detenido a un examen científico, tendiente a determinar la dosificación del alcohol en la sangre o en el organismo ${ }^{2}$. Dicho examen debía verificarse en un laboratorio especializado, dependiente del Servicio Médico Legal o en establecimientos médicos con la supervigilancia de aquél.

2. Prueba respiratoria y examen de alcoholemia en el texto original de la Ley $N^{\circ} 18.290$.

Complementando el tratamiento penal de la conducción en estado de ebriedad, que tipificaba la Ley $\mathrm{N}^{\circ} 17.105$, la Ley $\mathrm{N}^{\circ} 18.290^{3}$ se mantuvo originalmente en el plano del derecho administrativo sancionador ${ }^{4}$. Por este motivo, ya en su texto original contenía, también, disposiciones referentes a pruebas y exámenes de detección de alcohol.

En cuanto a las pruebas, el artículo 189 establecía: “Carabineros podrá someter a cualquier conductor a una prueba respiratoria o de otra naturaleza, destinada a detectar la presencia de alcohol en el organismo".

Respecto de los exámenes, el artículo $190^{5}$, en sus dos primeros incisos, señalaba: "El conductor o peatón que haya tenido intervención en un accidente de tránsito del que resulten lesiones o muerte, será sometido a un examen de alcoholemia. Si sólo resultaren daños, Carabineros podrá someterlo a dicho examen.l Los funcionarios de Carabineros llevarán inmediatamente al conductor o peatón a los Servicios de Asistencia Pública, Hospitalarios o Postas de

${ }^{2}$ Artículo 122 inciso $2^{\circ}$ de la Ley $\mathrm{N}^{\circ} 17.105$.

${ }^{3}$ Publicada en D.O. de 7 de febrero de 1984.

${ }^{4}$ Establecía en su artículo 115: "Ninguna persona podrá conducir un vehículo cuando se encuentre en condiciones fisicas deficientes o bajo la influencia del alcohol, drogas o estupefacientes". Dicha prohibición se relacionaba con el establecimiento en su artículo $197 \mathrm{~N}^{\circ} 1$, como infracción o contravención gravísima, "conducir un vehículo bajo la influencia del alcohol, drogas o estupefacientes".

${ }^{5}$ Véase el artículo 275 del Decreto con fuerza de ley N³068, publicado en D.O. de 31 de octubre de 1964. 
Primeros Auxilios de los Servicios de Salud, donde se le extraerá sangre para efectuar el análisis correspondiente".

Se aprecia que nuestro ordenamiento jurídico, tradicionalmente, ha distinguido entre "pruebas" y "exámenes" aptos para detectar y medir la concentración de alcohol en el organismo del sujeto.

\section{Principales modificaciones posteriores en la materia.}

La Ley $\mathrm{N}^{\circ} 19.495^{7}$, en este punto, fundamentalmente dispuso que las pruebas y exámenes señalados, respectivamente, en los artículos 189 y 190 LT., también serían procedentes para detectar la presencia de estupefacientes o sustancias sicotrópicas.

Pero, además, confundió los términos que siempre se habían empleado, estableciendo que Carabineros podría practicar exámenes de detección, en los casos de los artículos 189 inciso $2^{\circ}$ (referente a quien se apreste a conducir sin estar en plenitud de facultades para ello) y 190 (referente al conductor y el peatón que hayan participado en un accidente de tránsito con resultado de lesiones o muerte). Con ello, se tornó difusa la distinción antes señalada entre "pruebas" y "exámenes".

La Ley $\mathrm{N}^{\circ} 19.925^{\circ}$ acertadamente vino a corregir el defecto. Esto en virtud de la incorporación del artículo $115 \mathrm{~A}$ inciso $3^{\circ} \mathrm{LT}$., en que se estableció, de manera general, que el estado de ebriedad o la influencia del alcohol podían ser probados, entre otros medios, por el nivel de alcohol presente en el flujo sanguíneo que conste en el "informe de alcoholemia" o en el "resultado de la prueba respiratoria practicada por Carabineros". También, por la agregación al artículo 189 de los incisos $3^{\circ}$ a $6^{\circ}$. En sín-

${ }^{6} \mathrm{El}$ inciso $3^{\circ}$, que no tiene relevancia aquí, finalmente, disponía: “El examen de alcoholemia tendrá el mérito probatorio del informe pericial y el funcionario que lo practique estará exento de la obligación de prestar juramento, y no requerirá de nombramiento especial. El informe contendrá la firma del funcionario que lo haya efectuado y, en todo caso, deberá revisarlo el Jefe del respectivo establecimiento".

${ }^{7}$ Publicada en D.O. de 8 de marzo de 1997. Su rúbrica denotaba una finalidad específica: Modifica la Ley $N^{\circ} 18.290$, Ley de Tránsito, en lo relativo a la obtención de licencias de conducir; pero, en verdad, resultó miscelánea y de consecuencias penales bastante importantes.

${ }^{8}$ En virtud de la reforma operada por la Ley $\mathrm{N}^{\circ} 19.495$, el texto del artículo 190 inciso $1^{\circ}$ pasó a ser el siguiente: "El conductor y el peatón que hayan tenido participación en un accidente de tránsito del que resulte lesiones o muerte serán sometidos a examen destinado a establecer la presencia de alcohol o de estupefacientes o sustancias sicotrópicas en su cuerpo. En estos casos, los funcionarios de Carabineros deberán practicar al conductor y peatón los exámenes respectivos y, de carecer en el lugar de los elementos técnicos necesarios para ello, los llevarán de inmediato al más próximo servicio de asistencia pública, hospital o posta de primeros auxilios de los servicios de salud, para tales fines".

${ }^{9}$ Publicada en D.O. de 19 de enero de 2004. 
tesis, se extrae de ellos que Carabineros realiza la "prueba" de detección y, cuando su resultado es la constatación preliminar del estado de ebriedad, el sujeto debe ser conducido a un hospital para la práctica de los "exámenes" a que se refiere el artículo 190. La corrección puede observarse, asimismo, cuando distingue entre "prueba respiratoria (u otra) practicada por Carabineros" y "alcoholemia", en caso de accidentes de los que resulten lesiones o muerte, en el artículo 190.

El legislador olvidó, en cambio, corregir el artículo 189 inciso $2^{\circ}$, que, por consiguiente, continuó con su equivocada referencia a los exámenes que puede realizar Carabineros. Ésta subsiste, reubicada, hasta hoy ${ }^{10}$.

El texto de la Ley $\mathrm{N}^{\circ} 18.290$, fue refundido, coordinado y sistematizado como Decreto con fuerza de ley $\mathrm{N}^{\circ} 1^{11}$. Debido a ello, el contenido de los artículos 189 y 190 se desplazó, respectivamente, a los artículos 182 y 183. Éstos, con algunas modificaciones posteriores, permanecen hasta la actualidad.

\section{Pruebas y exámenes de detección de alcohol y drogas en la legislación vigente.}

De la tradición legislativa en esta materia, se desprende una distinción aplicable hasta hoy, entre pruebas de detección y exámenes científicos.

Las pruebas de detección son aplicadas directamente por funcionarios de Carabineros, deseablemente in situ, y por lo general son respiratorias. Los exámenes no se practican por Carabineros, sino por profesionales que se desempeñan en el área de la salud y, por lo tanto, es necesario conducir al sujeto a un establecimiento de salud habilitado por el Servicio Médico Legal, donde se extraerá una muestra de sangre para su análisis; esto último, de conformidad con lo dispuesto en la Resolución $\mathrm{N}^{\circ} 8.833$ exenta, emitida por la Dirección Nacional del Servicio Médico Legal, que lleva por título: Aprueba instrucciones y normativa técnica sobre exámenes de alcoholemia, y fue publicada en el D.O. de 30 de septiembre de 2010.

En la actualidad, las pruebas y exámenes de detección de alcohol y drogas están regulados, básicamente, en los artículos 182 y 183 LT. Se puede esquematizar la regulación efectuada por estas disposiciones, como sigue.

a) Casos en que se establece el sometimiento a pruebas de detección de alcohol o drogas. El artículo 182 otorga a Carabineros la facultad de someter a una prueba respiratoria o de otra naturaleza, destinada a detectar la presencia de alcohol en el organismo o acreditar el hecho de conducir bajo la influencia de estupefacientes o sustancias sicotrópicas, a

\footnotetext{
${ }^{10}$ Véase el artículo 182 inciso $2^{\circ} \mathrm{LT}$.

${ }^{11}$ Publicado en D.O. de 29 de octubre de 2009.
} 
determinados sujetos. Puede ser sometido a tal prueba cualquier conductor (inciso $1^{\circ}$ ). También puede serlo toda persona respecto de la cual se tema fundadamente que se apresta a conducir un vehículo en lugar público y que presente signos externos de no estar en plenitud de facultades para ello (inciso $2^{\circ}$ ).

El artículo 183 inciso $1^{\circ}$ reitera la atribución de Carabineros ya indicada, para someter a pruebas de detección a cualquier conductor. Sin tener carácter excluyente, la disposición destaca la posibilidad de emplear una "prueba respiratoria evidencial" [sic ${ }^{12}$. El inciso $2^{\circ}$, por su parte, señala medidas para garantizar la precisión de la prueba practicada. Específicamente, que deberá ser realizada con instrumentos certificados por el Ministerio de Transportes y Telecomunicaciones, conforme a las características técnicas que defina el reglamento, distinguiendo entre aquellos que son capaces de detectar la conducción bajo la influencia del alcohol, de los otros.

El artículo 183, desde sus orígenes, tenía por objeto señalar aquellos casos en que era necesaria la realización del examen de alcoholemia. Debe recordarse que su numeración es producto de la reubicación que sufrió al refundirse y sistematizarse el texto de la Ley $\mathrm{N}^{\circ} 18.290$, por obra del Decreto con fuerza de ley $\mathrm{N}^{\circ} 1$, y que originalmente era el artículo 190 LT. ${ }^{13}$. Los actuales incisos $1^{\circ}$ y $2^{\circ}$ fueron incorporados por la Ley $\mathrm{N}^{\circ}$

${ }^{12}$ En la historia de la Ley $\mathrm{N}^{\circ} 20.580$ quedó constancia de que, la incorporación de una mención expresa de la prueba evidencial [sic], tuvo por objeto reforzar su uso, mediante su fomento y regulación, tendiente a sustituir el más engorroso examen de alcoholemia. En el debate, la entonces secretaria ejecutiva de la Comisión Nacional de Seguridad de Tránsito, señora María Francisca Yáñez, expuso: "Se incorpora el alcotest evidencial [sic], como una prueba válida, acelerando el procedimiento de fiscalización que realiza Carabineros, sin necesidad de trasladar al infractor hasta un centro de salud público autorizado por el Servicio Médico Legal para practicar la alcoholemia. Esto demora, en algunos casos más de 4 horas, con la necesidad de levantar el punto de fiscalización". Por su parte, el asesor legislativo del Ministro de Transportes y Telecomunicaciones, señor Juan Carlos González, explicó que "se pretende incorporar la tecnología, utilizada internacionalmente, de alcotest evidencial [sic], que es una prueba respiratoria que entrega una información exacta en cuanto a la graduación alcohólica que la persona presenta en su cuerpo. Las pruebas actuales sólo entregan una referencia aproximada. La realización de alcoholemia no es un procedimiento muy eficaz, puesto que implica levantar el punto de fiscalización para llevar al infractor a un centro asistencial para practicarle el examen", todo en Historia de la Ley N²0.580 (Biblioteca del Congreso Nacional), disponible en: www.bcn.cl. Se comprende, en todo caso, que el verdadero problema de las pruebas respiratorias consiste en su fiabilidad. $\mathrm{O}$ sea, es de orden técnico o científico y no jurídico pues, de conformidad con el artículo 295 CPP., no existen restricciones a su respecto.

${ }^{13}$ Los incisos $1^{\circ}$ y $2^{\circ}$ del artículo 190 LT., tal y como quedaron dispuestos por la Ley $\mathrm{N}^{\circ} 19.925$, actualmente son los incisos $3^{\circ}$ y $4^{\circ}$ del artículo 183. 
$20.580^{14}$. Si se indaga en la historia de ésta, puede apreciarse que, en un comienzo, el Ejecutivo sólo pretendía rebajar las tasas de alcoholemia a partir de las cuales se consideraran cometidos los delitos de conducción bajo la influencia del alcohol y conducción en estado de ebriedad o bajo la influencia de sustancias estupefacientes o sicotrópicas y aumentar sus penas. Sin embargo, a poco andar, se incorporó una indicación del Gobierno, en que propuso incorporar al artículo $183 \mathrm{LT}$. dos nuevos incisos, $1^{\circ}$ y $2^{\circ}$, que son los que ahora analizamos.

Como en la estructura de la Ley del Tránsito, la disposición encargada de establecer la facultad de Carabineros para aplicar pruebas de detección, siempre ha sido la que ahora se sitúa en el artículo 182 (antiguo artículo 189), parece que lo correcto habría sido sustituir su inciso 1, por la actual y más moderna redacción, que quedó erróneamente situada en el artículo 183 inciso $1^{\circ}$. Y a continuación, siempre en el artículo 182, incorporar un nuevo inciso $2^{\circ}$, que se correspondería con el texto del actual inciso $2^{\circ}$ del artículo 183 .

Ello no ocurrió, y así la lectura de los artículos 182 y 183 da la impresión, por un lado, de que los primeros incisos de cada artículo señalan prácticamente lo mismo, lo que es correcto; y, por otro, que se ha perdido la nitidez de la distinción entre pruebas de detección (aplicadas por Carabineros) y examen de alcoholemia (extracción de sangre). Este enrarecimiento es fruto, en parte, de la "invasión" de que fue objeto el artículo 183 por parte de la pruebas de detección, recién comentada, pero también de la confusión de términos que produjo la Ley $\mathrm{N}^{\circ} 19.495$, la cual se refirió indistintamente a "pruebas" y "exámenes". Pese a que la Ley $\mathrm{N}^{\circ} 19.925$ corrigió en gran parte el problema, aún puede apreciarse cómo, equivocadamente, el inciso 2 del artículo 182 se refiere a la práctica de "exámenes" por funcionarios de Carabineros.

Por otra parte, el inciso final del artículo 183 dispone que el conductor y el peatón que hayan tenido participación en un accidente de tránsito del que resulten lesionados o muertos, serán sometidos a una prueba respiratoria o de otra naturaleza, destinada a establecer la presencia de alcohol o de sustancias estupefacientes o sicotrópicas en sus cuerpos.

En síntesis, el artículo 182, y el artículo 183 incisos $1^{\circ}$ y $2^{\circ}$, se refieren a las pruebas de detección de alcohol, y también de drogas, que Carabineros puede aplicar. Existe la facultad general de aplicar las pruebas a los sujetos y en los casos que las disposiciones señaladas indican. El artículo 183 inciso final, en cambio, establece el deber de aplicar tales pruebas, en la hipótesis que describe.

${ }^{14}$ Publicada en D.O. de 15 de marzo de 2012. 
b) Casos en que se establece el sometimiento a examen de alcoholemia. Las situaciones en que un sujeto habrá de ser sometido a un examen de alcoholemia, se desprenden tanto del artículo 183, incisos $2^{\circ}$ y $4^{\circ}$, como del artículo 197 LT. Son las siguientes:

i) El examen de alcoholemia podrá realizarse si, durante un procedimiento de fiscalización, Carabineros no cuenta con el instrumento para la realización de la prueba de detección. A nuestro juicio, dicho procedimiento es el que se desarrolla a través de controles de rutina, aleatorios, motivados por la existencia de indicios (conducción irregular, etc.) o efectuados tras haberse producido un hecho de tránsito del que, incluso, no resulten lesionados o muertos. A diferencia de los casos restantes, la derivación del conductor es aquí facultativa, según dispone el artículo 183 inciso $2^{\circ}$, parte final.

ii) El examen de alcoholemia deberá realizarse, respecto del conductor y el peatón que hayan tenido participación en un accidente de tránsito del que resulten lesionados o muertos, en dos situaciones. En primer lugar, cuando los funcionarios de Carabineros carezcan en el lugar de los elementos técnicos necesarios para practicar las pruebas de detección, según dispone el artículo 183 inciso final. Pero también en otros casos en que, de hecho, sea imposible practicar tales pruebas como, por ejemplo, cuando el conductor o peatón se encuentra inconsciente o no pueda ser sometido al procedimiento por sufrir determinadas lesiones, o una hemorragia, etc.

iii) El examen de alcoholemia deberá realizarse, también, respecto de cualquier conductor que haya sido sometido a una prueba de detección por parte de funcionarios de Carabineros y, de cuyo resultado, se desprenda que ha incurrido en el delito de conducción en estado de ebriedad o bajo la influencia de estupefacientes o sicotrópicos, según lo dispone el artículo 197 inciso final. A esta situación se refiere, a nuestro juicio, el artículo 183 inciso final, con la oración "o de proceder la práctica de la alcoholemia"15.

iv) Finalmente, el examen de alcoholemia deberá realizarse respecto de cualquier conductor que haya sido sometido a una prueba de detección por parte de funcionarios de Carabineros y, de cuyo resultado, se desprenda que ha incurrido en el delito de conducción bajo la influencia del alcohol (artículo 193 LT.), siempre que el propio conductor lo solicite. Esta hipótesis se desprende de relacionar el artículo 197 inciso $7^{\circ} \mathrm{LT}^{16}$ con el

${ }^{15}$ Lo que implica que la obligatoriedad sólo se refiere al conductor, y no al peatón. Pero esto es secundario, dada la facultad que de todos modos posee Carabineros, según se ha expresado en $4, b), i$ ).

${ }^{16}$ Dispone éste: "Si el conductor se encuentra bajo la influencia del alcohol, se procederá a cursar la denuncia correspondiente por la falta sancionada en el artículo 193". No se aplica a este caso la obligatoria conducción del sujeto a un establecimiento hos- 
artículo 8,2 letra c) de la Convención americana de los derechos humanos y los artículos 93 letra c) y 183 CPP. pues, habiendo adquirido ya el conductor la calidad de imputado, goza del derecho a contar con los medios adecuados para la preparación de su defensa, dentro de los que corresponde que se disponga por el fiscal, como diligencia de investigación, el examen que se comenta. Esto es evidente, dada la premura que existe en averiguar las tasas respectivas, cosa que importa tanto para los órganos de persecución como, eventualmente, para el imputado ${ }^{17}$. $\mathrm{Al}$ respecto cabe destacar que, en el derecho comparado, se establece la posibilidad de llevar a cabo una segunda prueba o examen, a efectos de contraste ${ }^{18}$.

Vinculado con las situaciones que se acaban de referir, es que el artículo 183 inciso $3^{\circ}$, señala: "Cuando fuere necesario someter a una persona a un examen científico para determinar la dosificación del alcohol en la sangre o en el organismo, los exámenes podrán practicarse en cualquier establecimiento de salud habilitado por el Servicio Médico Legal, de conformidad a las instrucciones generales que imparta dicho Servicio. El responsable del establecimiento arbitrará todas las medidas necesarias para que dichos exámenes se efectuien en forma expedita y para que los funcionarios de Carabineros empleen el menor tiempo posible en la custodia de los imputados que requieran la práctica de los mismos".

\section{LA SITUACIÓN ANTERIOR A LA ENTRADA EN VIGENCIA DE LA LEY N ${ }^{\circ} 20.770$. \\ EL RÉGIMEN DE PRESUNCIONES}

La previsión legal de algún mecanismo, tendiente a evitar la oposición del sujeto que corresponda, a la práctica de exámenes de detección de

pitalario para la práctica del examen de alcoholemia, dispuesto en el inciso $10^{\circ} \mathrm{del}$ mismo artículo, dado que éste sólo se remite a la situación del conductor sometido a una prueba de detección que arroja un resultado considerado por la ley como estado de ebriedad o influencia de sustancias estupefacientes o sicotrópicas. Esto, porque la disposición se remite a "las circunstancias establecidas en los dos incisos precedentes", que justamente parten de la base de dicho supuesto.

${ }^{17}$ Por ejemplo, si de la prueba respiratoria apenas resulta que la tasa de alcohol es de 0.3 gramos por mil de alcohol en la sangre y parece conveniente averiguar si, de una alcoholemia, se obtiene una tasa menor. En todo caso, debe tenerse presente que el Servicio Médico Legal ha instruido, en la Resolución $N^{\circ} 8.833$ antes citada, que las extracciones de sangre deben realizarse, también, a solicitud de particulares.

${ }^{18}$ Así en España, el artículo 22,1, inciso $2^{\circ}$ del Reglamento General de Circulación (Real Decreto N 1428/2003), establece: "A petición del interesado, o por orden judicial, se podrán repetir las pruebas a efectos de contraste, que podrán consistir en análisis de sangre, orina u otros análogos". 
sustancias capaces de perturbar sus facultades físicas y psíquicas, en el ámbito del tránsito, en ningún caso es nueva.

Ya la Ley $\mathrm{N}^{\circ} 17.105$ se ocupaba del problema, a través del establecimiento de una presunción. Su artículo 122, a propósito de la regulación del examen de alcoholemia, disponía en el inciso $2^{\circ}$ : " $L a$ circunstancia de negarse el detenido a dicho examen será apreciada por el Juez como una presunción, a la que podrá dar valor suficiente para establecer la embriaguez del acusado" 19 .

Por otra parte, en el ámbito de la regulación del tránsito, la Ley $\mathrm{N}^{\circ}$ 19.495 estableció las bases sobre las cuales discurriría la regulación posterior en la lógica de las presunciones, incluyendo el recientemente derogado artículo 182 inciso $5^{\circ} \mathrm{LT}$. En concreto, aquélla reemplazó el primitivo artículo 190 LT. e incorporó, en la disposición nueva, un inciso $3^{\circ}$, del siguiente tenor: "La negativa injustificada a someterse a los exámenes establecidos en el artículo 189 e inciso primero de este artículo, o la circunstancia de huir del lugar donde hubiese ocurrido el accidente, será considerada como presunción legal del estado de ebriedad o de intoxicación por estupefacientes $o$ sustancias sicotrópicas, según el caso".

La Ley $\mathrm{N}^{\circ}$ 19.925: Sobre expendio y consumo de bebidas alcohólicas, derogó el libro II de la Ley $\mathrm{N}^{\circ} 17.105^{20}$, intitulado: "De la penalidad de la embriaguez". Supuso, además, una revisión global del tópico conformado por la ingesta de alcohol u otras drogas vinculado a la conducción vehicular. Formalmente, debe recordarse que la Ley $N^{\circ} 19.925$ trasladó el tratamiento de este asunto a la Ley $\mathrm{N}^{\circ} 18.290$ cuyo texto, a partir del año 2009, se encuentra refundido, coordinado y sistematizado como Decreto con fuerza de ley $\mathrm{N}^{\circ} 1$.

La señalada Ley $\mathrm{N}^{\circ} 19.925$ incorporó un nuevo artículo 190 inciso $3^{\circ}$ LT., que luego, por obra del Decreto con fuerza de ley $\mathrm{N}^{\circ} 1$, pasó a ser el artículo 183 inciso $5^{\circ} \mathrm{LT}$. Éste disponía lo siguiente: "La negativa injustificada a someterse a las pruebas o exámenes a que se refieren este articulo y el artículo 182, o la circunstancia de huir del lugar donde se hubiere

${ }^{19}$ Con el objeto de que pueda apreciarse íntegramente el paralelismo con el artículo 183 inciso $5^{\circ} \mathrm{LT}$., al que nos referiremos inmediatamente, cabe señalar que, además, el artículo 122 inciso $1^{\circ}$ de la Ley $\mathrm{N}^{\circ} 17.105$ disponía: "La circunstancia de huir del lugar donde se hubiere cometido alguno de los delitos a que se refiere el artículo precedente, será apreciada por el juez como una presunción que podrá ser suficiente para establecer la culpabilidad del acusado". El mencionado "artículo precedente" tipificaba el delito de conducción en estado de ebriedad.

${ }^{20}$ La Ley $\mathrm{N}^{\circ} 19.925$, en su artículo 58, dispuso: "Derógase el Libro II de la ley $N^{o}$ 17.105, de Alcoholes, Bebidas Alcohólicas y Vinagres. Las disposiciones legales que hagan referencia al Libro II de la ley $N^{\circ} 17.105$ se entenderán hechas a esta ley, en las materias a que dichas disposiciones se refieren". 
ejecutado la conducta delictiva, en su caso, serán apreciadas por el juez como un antecedente calificado, al que podrá dar valor suficiente para establecer el estado de ebriedad o influencia de sustancias estupefacientes o sicotrópicas en que se encontraba el imputado"21.

Puede apreciarse que esta disposición, al igual que su antecesora, contenía un mecanismo tendiente a estimular la realización de las pruebas de detección, a través de la amenaza de tener por acreditados elementos constitutivos de la responsabilidad penal, sobre la base de una presunción simplemente legal ${ }^{22}$. Su carácter ha sido confirmado por la jurisprudencia ${ }^{23}$, pese a que estaba redactada en términos bastante tímidos, lo que resulta evidente al compararla con aquellas que la precedieron. Timidez que, por cierto, halla su explicación en que el legislador de la época fue consciente acerca de lo impropio que resultaba ya, pretender compeler al juez a tener por probada la culpabilidad mediante esta vía ${ }^{24}$.

El inciso final del artículo $183 \mathrm{LT}$., transcrito y analizado, fue derogado por el artículo $1 \mathrm{~N}^{\circ} 2$ de la Ley $\mathrm{N}^{\circ} 20.770^{25}$.

${ }^{21}$ La disposición original se refería a "las pruebas o exámenes a que se refieren este artículo y el artículo 189".

${ }^{22}$ En este sentido, claramente, la sentencia de la Corte de Apelaciones de San Miguel, de 28 de enero de 2013, rol 48-2013. En su considerando $7^{\circ}$ dijo: " $E n$ sintesis, el someterse al examen de alcoholemia, no convierte ipso iure tal cometido en colaboración sustancial, puesto que se colige de la articulación de los distintos elementos concurrentes que el sujeto simplemente lo ha hecho en aras del procedimiento regular y de primer factum, básicamente en su propio beneficio, pues tal conducta ligada con el resultado del examen podría haber indicado una dosificación de alcohol en la sangre que lo hubiera eximido de responsabilidad penal, o bien, se le hubieren formulado cargos por una figura menor, de manejo bajo la influencia del alcohol, en cambio una actitud refractaria habría sido de inmediato contraria a sus intereses, ya que una eventual negativa a practicarse el examen pudo provocar una presunción iuris tantum en su contra, de manejo en estado de ebriedad'. Cfr. Silva SiLva, Hernán, El delito de manejar en estado de ebriedad (2a edición, Santiago, Editorial Jurídica de Chile, 2009), p. 107.

${ }^{23}$ Pueden consultarse las siguientes resoluciones: sentencia de la Corte Suprema, de 20 de octubre de 2008, rol 4905-08; sentencia de la Corte Suprema, de 12 de septiembre de 2012, rol 5461-12; sentencia de la Corte de Apelaciones de Santiago, de 7 de mayo de 2014, rol 551-2014.

${ }^{24}$ Quedó asentado en la Historia de la Ley $N^{\circ} 19.925$, disponible en: www.bcn. cl: "Las Comisiones Unidas se mostraron de acuerdo con las propuestas del Ejecutivo de eliminar las presunciones contempladas en estos tres articulos, ya que son inconciliables con el sistema de libertad en la valoración de la prueba que consagra el nuevo Código Procesal Penal, pero dando a los hechos que las constituyen el carácter de un antecedente calificado, que deberá evaluar el tribunal'.

${ }^{25}$ Publicada en D.O. de 16 de septiembre de 2014. 


\section{GÉNESIS DEL ARTícUlo 195 BIS DE LA “LEY DEL TRÁNSITO”}

La disposición que tipifica el delito que nos hemos propuesto analizar no se contenía en el proyecto de ley original, emanado del Poder Ejecutivo. Recién durante las sesiones de la Comisión de Constitución, Legislación, Justicia y Reglamento del Senado, se advirtió la necesidad de realizar ciertos ajustes, destinados a perfeccionarlo y complementarlo. Dentro de éstos, la posibilidad de "tipificar como ilícitos independientes la fuga del lugar del accidente o la negativa a hacerse el examen de alcoholemia, a fin de evitar incentivos perversos para burlar las penas establecidas en esta iniciativa" 26 .

La idea se materializó a través de una indicación de la presidente de la República, que tenía por objeto sustituir el inciso final del artículo 183 LT. por una disposición que, en su texto, ya contenía el germen del actual artículo 195 bis y en que, por primera vez, apareció de manifiesto la intención de sancionar el comportamiento que ahora examinamos. Esto último, tipificándolo en los términos siguientes: "La negativa injustificada a someterse a las pruebas o exámenes a que se refiere este artículo en el caso del inciso anterior [...]". Se advierte, en consecuencia, que esta iniciativa aludía a una situación muy específica, normada en el entonces inciso penúltimo ${ }^{27}$, a diferencia de la remisión más general que efectuaba la presunción a que hemos hecho referencia.

En el seno de la misma Comisión se prefirió agregar una disposición enteramente nueva, que reflejara la iniciativa presidencial, dentro del título $17^{\circ}$, párrafo $1^{\circ}$ de la Ley del Tránsito, rubricado: "De los delitos y cuasidelitos". Se quiso establecer, además, una distinción en cuanto a la pena, la que se consideró debía ser más grave en caso que la negativa se manifestara en el contexto de un hecho de tránsito, que hubiese desembocado en la producción de determinados resultados ${ }^{28}$.

${ }^{26}$ Historia de la Ley $N^{\circ} 20.770$, disponible en: www.bcn.cl.

${ }^{27} \mathrm{El}$ entonces inciso penúltimo, que actualmente es el inciso final, del artículo 183, establece: "Sin perjuicio de lo dispuesto en el articulo anterior, el conductor y el peatón que hayan tenido participación en un accidente de tránsito del que resulten lesionados o muertos serán sometidos a una prueba respiratoria o de otra naturaleza destinada a establecer la presencia de alcohol o de sustancias estupefacientes o sicotrópicas en sus cuerpos. En esos casos, los funcionarios de Carabineros deberán practicar al conductor y peatón las pruebas respectivas y, de carecer en el lugar de los elementos técnicos necesarios para ello, $o$ de proceder la práctica de la alcoholemia, los llevarán de inmediato al establecimiento de salud más próximo. Se aplicarán al efecto las reglas del inciso precedente".

${ }^{28} \mathrm{El}$ profesor Matus manifestó el parecer, acogido por los miembros de la Comisión, de que "debería considerarse una ubicación distinta para esta disposición, dentro del titulo de las penalidades, y distinguir según el resultado final del accidente, a efectos de imponer una pena extra alta si los resultados son muy perjudiciales para terceros, o 
Se propuso así la incorporación de un nuevo artículo 195 bis LT. que, al ser aprobada la modificación legal, conservó dicha numeración y también, en términos casi idénticos, su contenido. Como consecuencia de lo anterior se propuso, también, suprimir el inciso $5^{\circ}$ del artículo 183 , que contenía la presunción a que hemos hecho referencia.

Cabe advertir cuán pacífica resultó la tramitación parlamentaria, para la creación del delito de negativa injustificada a las pruebas o exámenes de detección de alcohol o drogas ${ }^{29}$.

\section{SOBRE EL BIEN JURÍDICO PROTEGIDO}

\section{El motivo del legislador para incriminar el comportamiento: la facilidad} probatoria.

Resulta útil, para este análisis, fijar en primer lugar el motivo del legislador, en el establecimiento de este delito. A nuestro juicio, aquél es puramente funcional, y consiste en el interés por facilitar la obtención de un medio de prueba, que dé cuenta de la concentración de alcohol en el organismo de un conductor ${ }^{30}$.

Lo anterior es comprensible, desde un punto de vista práctico, si se enlaza con el carácter predominantemente formal que ostentan en la actualidad los delitos estructurados sobre la base de la conducción habiendo ingerido alcohol. En éstos, la realización del injusto típico parece satisfacerse con la sola actividad de conducir habiendo superado determinadas tasas de esta sustancia, predeterminadas por la ley, las que, además, obligan a remitirse, ya sea al delito de conducción bajo la influencia del alcohol (artículo 193 LT.), o al de conducción en estado de ebriedad (artículo

una pena baja si tal resultado nocivo no tuvo lugar": Historia de la Ley $N^{\circ} 20.770$, disponible en: www.bcn.cl.

${ }^{29} \mathrm{Cfr}$. Alonso Rimo, Alberto, El delito de negativa a someterse a las pruebas de alcoholemia o de detección drogas tóxicas desde la perspectiva de la reforma penal de 2007, en Vidales Rodríguez, Caty - Mera Redondo, Antonio (coordinadores), Seguridad vial (Especial referencia a la reforma operada en el Código Penal mediante la Ley Orgánica 15/2007, de 30 de noviembre) (Valencia, Tirant lo Blanch, 2008), pp. 294-295. Ahí se da cuenta de la polémica generada por la incorporación de este delito al ordenamiento penal español en el Código Penal de 1995, hecho que supuso la manifestación de fuertes opiniones en su contra, durante el debate parlamentario e, incluso, un cierto respaldo de tales posturas por parte del Tribunal Supremo de aquel país. A esto habría que agregar un enconado debate doctrinal.

${ }^{30}$ Gutiérrez Rodríguez, María - García del Blanco, Victoria - Martín Lorenzo, María - Sanz-Díez de Ulzurrun Lluch, Marina, Protección penal de la seguridad vial (Valencia, Tirant lo Blanch, 2009), p. 321; Alonso Rimo, Alberto, cit. (n. 29), p. 306. 
196 LT.), atendiendo solamente a los resultados objetivos de la prueba o examen llevados a cabo (artículo 111 inciso $2^{\circ}$ LT.).

Lo innecesario de una genuina influencia del alcohol o, en su caso, ebriedad del sujeto ${ }^{31}$, que son indicadores de la real falta de aptitud de éste en el caso concreto, para desempeñarse en el ámbito del tráfico y, por lo mismo, de la antijuricidad material de su comportamiento, más allá de la simple constatación de que se ha contravenido formalmente la norma ${ }^{32}$, ya permite un serio cuestionamiento de estas figuras. Así, su equivalente en el derecho español, ha merecido la calificación de delito de peligro presunto ${ }^{33}$.

Pero conocer el motivo del legislador para la incriminación -el facilitar la prueba de otro delito, que afecta la seguridad vial, o bien, la vida y salud de las personas-, no responde a la pregunta de cuál sea el bien jurídico protegido por este delito. Y es que la pura vinculación funcional que la negativa al sometimiento de pruebas o exámenes de detección, tiene con las figuras de conducción bajo la influencia del alcohol, o en estado de ebriedad o bajo la influencia de drogas, no constituye argumento para atribuir, automáticamente, los mismos objetos de tutela de éstos, a las figuras delictivas del artículo $195 \mathrm{bis}^{34}$.

\section{El posible bien jurídico protegido.}

Se trata, éste, de un delito que provoca serios cuestionamientos a la

${ }^{31}$ Distinción que, al parecer, es oriunda de nuestro país y que, nada más, es fruto de una evolución poco meditada, por cuya virtud el ilícito administrativo de conducir bajo la influencia del alcohol terminó siendo delito penal y, a la vez, quedó separado por una frontera puramente formal (tasa alcohólica) de su "pariente", la conducción en estado de ebriedad.

${ }^{32}$ Mir Puig, Santiago, Derecho penal. Parte general (9a edición, Barcelona, Reppertor, 2011), pp. 150-151.

${ }^{33}$ Por todos, Gallego Soler, Ignacio, El nuevo delito de conducción bajo los efectos del alcohol y las drogas (artículo 379.2 CP), en Mir PUiG, Santiago - CorCoy BIDASOLO, Mirentxu (directores), Seguridad vialy derecho penal (Valencia, Tirant lo Blanch, 2008), p. 158.

${ }^{34}$ Véase en este sentido, Alonso Rimo, Alberto, cit. (n. 29), p. 310. El autor, en términos muy gráficos, da el siguiente ejemplo: "la inobservancia de la orden de donar sangre para realizar un análisis de $\mathrm{ADN}$ a efectos de comprobar si el sujeto es el autor de un asesinato podría convertirse, en tanto supondría una disminución de los efectos preventivos del artículo 139, en un delito contra la vida [...]. Y esa misma solución, sin duda disparatada, sería aplicable en relación con un buen número de infracciones, que se verían de esta forma duplicadas sobre la base de la presencia de un peligro para el bien jurídico, sin duda remoto y etéreo, pero no en mayor medida que el que representa el comportamiento de negarse a someterse a las pruebas de alcoholemia para la seguridad del tráfico (o para la vida o la integridad de las personas)". 
hora de intentar precisar su objeto de tutela. De aquí que existan, en la doctrina comparada, diversas opiniones ${ }^{35}$.

A nuestro entender, la cuestión del bien jurídico debe abordarse mediante la formulación de una pregunta inicial: ¿ Es éste un genuino delito contra la seguridad vial o, si se prefiere, contra los bienes jurídicos individuales de quienes se ven involucrados en el ámbito de riesgo del tráfico vehicular? Al respecto, se debe concordar con quienes han advertido que no se comprende cómo el hecho de que un sujeto se niegue a facilitar la prueba de su ingesta de alcohol pueda, con tal comportamiento, afectar los referidos bienes jurídicos ${ }^{36}$.

Dicho de un modo más gráfico, quien ha afectado tales bienes jurídicos es el conductor que se ha desempeñado bajo la influencia del alcohol, en estado de ebriedad o, en su caso, bajo la influencia de drogas. Si este mismo conductor, luego, ante un requerimiento de la práctica de las pruebas o exámenes de detección, se niega, no está por este nuevo comportamiento volviendo a afectar aquéllos. La negativa a un "alcotest", o a la extracción de sangre, no resiste un examen de antijuricidad material, si se pretende que tal comportamiento está poniendo -concreta y actualmente- en peligro la vida o la salud de las personas. Lo mismo cabe concluir, si la lesividad se pretende examinar con referencia a la seguridad vial ${ }^{37}$.

Además, el delito de negativa del conductor a la práctica de las pruebas o exámenes de detección, no está directamente vinculado con la comisión de un delito de conducción bajo la influencia del alcohol, o en estado de ebriedad o bajo la influencia de drogas. La disposición del artículo 195 bis, simplemente, considera típica la negativa a la realización de las pruebas señaladas en los artículos 182 y 183 . Esta remisión, sin duda, significa que el delito en cuestión puede ser cometido por quien está completamente

${ }^{35}$ Gutiérrez Rodríguez, María - García del Blanco, Victoria - Martín Lorenzo, María - Sanz-Díez de Ulzurrun Lluch, Marina, cit. (n. 30), pp. 302-306. Los autores sintetizan el problema en España, exponiendo cuatro formas en que se ha abordado el problema interpretativo del objeto de tutela jurídico-penal: $i$ ) entender este delito como uno de desobediencia, en que tradicionalmente se entendió que resultaba afectado el denominado "principio de autoridad"; ii) considerarlo como un delito contra la seguridad vial y/o contra bienes de carácter individual (vida, salud y propiedad); iii) estimar que se trata de un delito pluriofensivo (se afectaría el principio de autoridad, más la seguridad vial y/o bienes de carácter individual); y, por último, iv) entenderlo como un delito contra la administración de justicia.

${ }^{36}$ Fernández BAUtista, Silvia, El delito de negativa a la realización de las pruebas de alcoholemia, en Mir Puig, Santiago - Corcoy Bidasolo, Mirentxu (directores), Seguridad vial y derecho penal (Valencia, Tirant lo Blanch, 2008), p.183; SiLva SiLva, Hernán, cit. (n. 22), p. 108.

${ }^{37}$ Alonso Rimo, Alberto, cit. (n. 29), pp. 306-308. 
sobrio y que, por lo mismo, al menos en este sentido no ha afectado con su conducta la seguridad vial, o bien, la vida o salud de las personas.

Un argumento adicional para estimar que el bien jurídico protegido en el artículo 195 bis, no es el mismo que el de las figuras tipificadas en los artículos 193 y 196 LT., está constituido por la regla concursal del inciso final de aquella disposición. Según ésta, la pena prevista para el delito de negativa, en el caso de "accidentes" que produzcan lesiones graves gravísimas o muerte de alguna persona, se impondrá al conductor conjuntamente con la que le corresponda por la responsabilidad que le pueda caber en el respectivo delito o cuasidelito. Esto, de conformidad con lo dispuesto en el artículo 74 CP. La referencia a este artículo hace evidente que, para la ley, el delito previo, que habrá afectado la seguridad vial, o bien, la vida o salud de las personas, y el delito de negativa, son de distinta especie pues, de lo contrario, el concurso real debiera acogerse, en principio, a la regulación efectuada por el artículo $351 \mathrm{CPP} .^{38}$.

Alterando lo que se ha descrito como "una larga tradición de prescindencia de delitos de mera desobediencia a la autoridad" 39 , propia del derecho penal chileno, todo indica que estamos ante una figura de desobediencia. Como se ha expresado, tomando por base el muy similar artículo 383 del Código Penal español: "En definitiva, se trataría de un requerimiento específico de agentes de la autoridad al que el sujeto en cuestión se niega" ${ }^{40}$.

El objeto de tutela es, en consecuencia, el denominado "principio de autoridad" ${ }^{41}$, aunque debe aclararse que, en su sentido original, este concepto se halla desacreditado y no se estima que satisfaga los criterios de un genuino bien jurídico-penal. Esto significa que la terminología se conserva, pero entendiendo que la expresión apunta a la tutela del buen

${ }^{38}$ Cfr. Montaner Fernández, Raquel, Delitos contra la seguridad vial, en Silva SÁnCHEZ (director), Lecciones de derecho penal. Parte especial ( $3^{\text {a }}$ edición, Barcelona, Atelier, 2011), p. 303; Miró Llinares, Fernando, Artículo 383, en Cobo del Rosal (Director), Comentarios al Código Penal. Segunda época (Madrid, Cesej, 2008), XI, pp. 753-754.

${ }^{39}$ Hernández Basualto, Héctor, Alcances del delito de desacato en el contexto de la Ley de Violencia Intrafamiliar, en Defensoría Penal Pública (editor), Informes en derecho. Doctrina procesal penal 2010 (Santiago, Editorial Atenas, 2011), p. 7. Aunque cabría reflexionar sobre el alcance de la falta establecida en el artículo $496 \mathrm{~N}^{\circ} 1 \mathrm{CP}$., que dispone: "El que faltare a la obediencia debida a la autoridad dejando de cumplir las órdenes particulares que ésta le diere, en todos aquellos casos en que la desobediencia no tenga señalada mayor pena por este Código o por leyes especiales".

${ }^{40}$ Fernández Bautista, Silvia, cit. (n. 36), p. 197.

${ }^{41}$ Silva Silva, Hernán, cit. (n. 22), p. 109. 
funcionamiento de los órganos o servicios públicos ${ }^{42}$, o de la "dignidad de la función pública por la trascendencia que para el cumplimiento de los fines del Estado tiene el respeto debido a sus órganos", como ha manifestado en España el Tribunal Supremo ${ }^{43}$.

\section{Visión panorámica del artículo 195 bis de la "Ley del tránsito"}

En virtud de la Ley $\mathrm{N}^{\circ} 20.770$, publicada en el D.O. de 16 de septiembre de 2014, se incorporó al texto de la Ley del tránsito, el artículo 195 bis, del siguiente tenor: "[Inciso $1^{\circ}$ ] La negativa injustificada de un conductor a someterse a las pruebas respiratorias u otros exámenes cientificos destinados a establecer la presencia de alcohol o de sustancias estupefacientes o psicotrópicas en el cuerpo, previstos en el artículo 182, será sancionada con multa de tres a diez unidades tributarias mensuales y con la suspensión de su licencia hasta por un mes./ [Inciso $2^{\circ}$ ] En caso de accidentes que produzcan lesiones de las comprendidas en el número $1^{\circ}$ del artículo 397 del Código Penal o la muerte de alguna persona, la negativa injustificada del conductor que hubiese intervenido en ellos a someterse a las pruebas respiratorias evidenciales [sic] o a los exámenes científicos señalados en el artículo 183 de esta ley para determinar la dosificación de alcohol en la sangre o la presencia de drogas estupefacientes o sicotrópicas, o la realización de cualquier maniobra que altere sus resultados, o la dilación de su práctica con ese mismo efecto, serán castigadas con la pena de presidio menor en su grado máximo, multa de once a veinte unidades tributarias mensuales, inhabilidad perpetua para conducir vehiculos de tracción mecánica y comiso del vehiculo con que se ha cometido el delito, sin perjuicio de los derechos del tercero propietario, que podrá hacer valer conforme a las reglas generales del Código Procesal Penal. Para los efectos de determinar la pena prevista en este inciso, será aplicable lo dispuesto en los

${ }^{42}$ Queralt Jiménez, Joan, Derecho penal español. Parte especial (6a edición, Barcelona, Atelier, 2010), p. 995, concibe este delito como uno de desobediencia, esto es, "un ataque a la capacidad prestacional de servicios públicos que incumbe en el ejercicio de sus funciones a los diversos poderes públicos”.

${ }^{43}$ Sentencia del Tribunal Supremo, de 31 de enero de 1990, citada por Miró LlinARES, Fernando, cit. (n. 38), XI, p. 751. Explica este autor que "en la actualidad, pues, no resulta compatible con la defensa de un derecho penal de un Estado social y democrático de derecho considerar que aquello digno de protección en el delito de desobediencia sea la jerarquía o autoridad como fines en sí mismos. Por el contrario, es el carácter instrumental de estos principios, relacionado con el correcto desarrollo de las funciones encomendadas por la Constitución a los poderes públicos y dirigidas, esencialmente, al servicio de los ciudadanos, lo que, al fin y al cabo, se convierte en el bien jurídico protegido por los delitos de atentado, resistencia y desobediencia a la autoridad". 
artículos 196 bis y 196 ter de esta ley./[Inciso 3] La pena prevista en el inciso anterior se impondrá al conductor conjuntamente con la que le corresponda por la responsabilidad que le pueda caber en el respectivo delito o cuasidelito, de conformidad con lo dispuesto en el artículo 74 del Código Penal.

El primer inciso contiene un tipo penal, al que se asocian penas copulativas: multa y suspensión de licencia de conducir.

El segundo es un tipo penal similar que, en principio, podría considerarse un supuesto calificado del primero, aunque como se advertirá presenta ciertas diferencias con aquél, que no sólo están constituidas por las circunstancias particulares de comisión en que se funda la agravación de la pena.

El tercero contiene una remisión expresa a la regla de acumulación aritmética de penas del artículo $74 \mathrm{CP}$., para el caso en que quepa imponer al conductor la pena prevista por el delito del inciso $2^{\circ}$, en una situación de concurso real con otro delito doloso o culposo.

\section{EL TIPO PENAL DEL ARTÍCULO 195 BIS INCISO PRIMERO}

\section{Descripción general.}

El comportamiento delictivo descrito en el inciso $1^{\circ}$ del artículo 195 bis, es el siguiente: "La negativa injustificada de un conductor a someterse a las pruebas respiratorias u otros exámenes cientificos destinados a establecer la presencia de alcohol o de sustancias estupefacientes o psicotrópicas en el cuerpo, previstos en el artículo 182".

Cabe, a continuación, realizar un análisis de los elementos típicos objetivos.

\section{Conducta típica.}

La ley se refiere a una negativa; esto es, a una denegación. "Denegar" es no conceder lo que se pide o solicita. En consecuencia, es indispensable que tal comportamiento del sujeto activo sea precedido por una solicitud o requerimiento, emanado de determinadas personas, aunque la ley no lo exprese en el tipo penal ${ }^{44}$.

Esto es perfectamente lógico si se piensa, por ejemplo, en que no tiene sentido el considerar delictiva la decisión de un conductor de seguir su camino, en vez de detenerse espontáneamente ante un control policial para solicitar ser sometido a la prueba de detección.

${ }^{44}$ Más claro en este sentido resulta el delito correspondiente tipificado en el artículo 383 del Código Penal español, que exige ser "requerido por un agente de la autoridad'. 
En doctrina y jurisprudencia comparadas se ha planteado que este delito, como expresión de desobediencia, presupone un requerimiento que cumpla con determinados requisitos. Son los siguientes: $i$ ) que emane de un agente de la autoridad competente que actúe en el ejercicio de sus funciones; ii) que sea expreso, terminante y claro; y iii) que contenga la información necesaria acerca de su obligatoriedad y las consecuencias jurídicas previstas en caso de no someterse al mismo ${ }^{45}$. A nuestro juicio, tales exigencias resultan perfectamente razonables y susceptibles de ser aplicadas en Chile.

El funcionario público competente para efectuar el requerimiento es uno de Carabineros de Chile, de acuerdo con la remisión que el inciso $1^{\circ}$ del artículo 195 bis hace al artículo $182 \mathrm{LT}$.

Un problema interpretativo se produce a la hora de plantearse, específicamente, cuál es el método de detección a cuyo sometimiento el sujeto se ve requerido, y cuya negativa podría considerarse delictiva a este título. Sucede que, pese a la amplitud de los términos del tipo que examinamos, que alude a "pruebas respiratorias u otros exámenes científicos", lo cierto es que se remite de modo puntual a aquellos previstos en el artículo 182. Y, como hemos ya observado, esta disposición establece únicamente la facultad de Carabineros de someter a cualquier conductor a pruebas de detección de alcohol, estupefacientes o sustancias sicotrópicas. No así al examen de alcoholemia, que se establece en los artículos 183 y $197^{46}$.

Probablemente esto es producto de la dispersión que la Ley del Tránsito presenta en su estructura interna, así como de las continuas, asistemáticas modificaciones que ha ido sufriendo con el tiempo. Pero hay que ser cuidadoso de cargar en cuenta del ciudadano este defecto, pasando por sobre las reglas de interpretación ${ }^{47}$ y el principio de taxatividad, consagrado constitucionalmente.

En relación con la forma de la conducta, la negativa puede exteriorizarse, mediante el lenguaje verbal o a través de ciertos signos inequívocos, o bien, ser implícita, es decir, inferirse de otros actos concluyentes en el mismo sentido ${ }^{48}$.

${ }^{45}$ Gutiérrez Rodríguez, María - García del Blanco, Victoria - Martín LoRenzo, María - Sanz-Díez de Ulzurrun Lluch, Marina, cit. (n. 30), p. 363; Miró LlinARES, Fernando, cit. (n. 38), XI, pp. 796-797.

${ }^{46}$ Debe recordarse que la mención que hace el artículo 182 inciso $2^{\circ}$ a "exámenes” es errónea y, por lo demás, sólo se circunscribe al caso de quien se apresta a conducir.

${ }^{47}$ Véase el artículo 23 CC.

${ }^{48}$ Gutiérrez Rodríguez, María - García del Blanco, Victoria - Martín LoRenzo, María - Sanz-Díez de Ulzurrun Lluch, Marina, cit. (n. 30), p. 341. 
La negativa del conductor debe ser injustificada. Tal expresión legal resulta discutible.

Ella puede interpretarse como una alusión a la antijuricidad de la conducta. La negativa estará justificada cuando el conductor se encuentre en alguna de aquellas situaciones en que el derecho permite la realización de un comportamiento típico. Es decir, cuando se encuentre amparado por una causal de justificación ${ }^{49}$.

Pero no parece que asignar tal sentido restringido a la disposición sea lo correcto. Desde luego, en un delito como el que nos ocupa, no tiene mayor utilidad una referencia específica al obrar ilícito, ya que la concurrencia de causales de justificación será probablemente una situación bastante excepcional ${ }^{50}$. Además, resulta incuestionable que ningún comportamiento amparado en una causal de justificación puede ser constitutivo de delito, aunque la ley nada diga en la redacción del precepto singular.

En un sentido amplio, la negativa injustificada puede entenderse como aquella que no resulta admisible, por faltar una explicación acerca de la no realización del comportamiento exigido, que se estime razonable desde la perspectiva del común de las personas, es decir, desde un punto de vista intersubjetivo. Será el juez el encargado de plasmar este criterio en el caso concreto. Así el temor fóbico a la práctica de determinados exámenes, como son las extracciones de sangre, podría considerarse justificación suficiente para una negativa, o el estado de conmoción o de estupor tras el acontecimiento, que dificulten o dilaten la práctica de la prueba respiratoria. A este respecto, surge la interrogante de si acaso basta con invocar un determinado motivo para tener por justificada la negativa o si, además, se requiere una acreditación del hecho de su existencia. Según nuestro parecer tal hecho, que constituye la base de una alegación exculpatoria del imputado, debiera ser materia de prueba por parte de éste durante el juicio ${ }^{51}$.

Se considera este delito como uno de mera actividad. La proyección inmediata de tal calidad en el ámbito de la imperfecta realización, es la imposibilidad de apreciar el delito frustrado.

Si bien, teóricamente, es posible la tentativa, la doctrina es reacia a

${ }^{49}$ En este sentido, respecto del delito de porte de armas cortantes o punzantes, en la hipótesis descrita por el artículo 288 bis inciso $2^{\circ} \mathrm{CP}$., véase la Sentencia de la Corte de Apelaciones de Concepción, de 29 de junio de 2012, rol 237-2012.

${ }^{50}$ Cfr. Fernández Bautista, Silvia, cit. (n. 36), p. 198. En España, el Reglamento General de Circulación excusa de la obligación de someterse a las pruebas de alcoholemia a aquellas personas que sufran lesiones, dolencias o enfermedades cuya gravedad impida la práctica de estas pruebas.

${ }^{51}$ En sentido similar, en el contexto de la anterior regulación, Silva SiLVA, Hernán, cit. (n. 22), pp. 106-107. 
considerarla. Esto sucede en las que cabría llamar "negativas únicas", porque el margen entre el principio de ejecución del delito y el término de los actos requeridos para que se consume, es muy estrecho. Pero lo mismo se sostiene, por otros motivos, en aquella situación en que hay una negativa inicial, seguida de un posterior sometimiento del sujeto, en un tiempo razonable. Ello debido a que, "la incriminación excepcional de la conducta de rehusar someterse a una pericia que puede ser utilizada en un procedimiento penal para probar la comisión de un delito carece de sentido cuando el sujeto accede a la postre a someterse a ella"52.

\section{Sujeto activo.}

En virtud de la expresa mención que realiza el artículo 195 bis inciso $1^{\circ}$, sujeto activo del delito es el conductor. Éste se encuentra definido por el artículo $2 \mathrm{~N}^{\circ} 9 \mathrm{LT}$., como "toda persona que conduce, maneja o tiene control fisico de un vehiculo motorizado en la vía pública; que controla o maneja un vehiculo remolcado por otro; o que dirige, maniobra o está a cargo del manejo directo de cualquier otro vehiculo, de un animal de silla, de tiro $o$ de arreo de animales".

Quizás con una amplitud mayor que la deseable para efectos penales, queda claro que es sujeto activo no sólo el conductor de un vehículo motorizado. $\mathrm{Ni}$, tampoco, únicamente el de un vehículo que requiera, para su manejo o control, de una licencia de conductor, como ha puesto de relieve nuestra jurisprudencia ${ }^{53}$.

En cambio, no es sujeto activo del delito "quien se apresta a conducir". $\mathrm{El}$ artículo 195 bis inciso $1^{\circ}$, inequívocamente, se remite en este punto tan solo al artículo 182 inciso $1^{\circ}$, dado que ambos coinciden en señalar al conductor, como la persona a quien Carabineros puede someter a la prueba de detección y que, si se niega, realiza objetivamente el tipo de delito. La voz "conductor" está definida legalmente con referencia a un verbo de acción en tiempo presente del modo indicativo ("conduce"); por lo tanto, no resulta admisible extender su alcance a momentos anteriores a la adquisición de tal calidad, sin caer en la analogía contra reo.

Lo dicho no obsta a la aplicación del artículo 182 inciso $2^{\circ}$, que faculta a Carabineros para practicar exámenes (pruebas) de detección a toda persona respecto de la cual tema fundadamente que se apresta a conducir un vehículo en lugar público y que presente signos externos de no estar en

\footnotetext{
${ }^{52}$ Gutiérrez Rodríguez, María - García del Blanco, Victoria - Martín Lorenzo, María - Sanz-Díez de Ulzurrun Lluch, Marina, cit. (n. 30), pp. 382-383.

${ }^{53}$ Últimamente, reiterando que el delito de conducción en estado de ebriedad puede cometerse desplazándose en bicicleta, véase la sentencia de la Corte de Apelaciones de Temuco, de 1 de septiembre de 2014, rol 728-2014.
} 
plenitud de facultades para ello. Ni impide que de esa manera se obtenga un medio de prueba de la tentativa de conducción bajo la influencia del alcohol, en estado de ebriedad o bajo la influencia de sustancias estupefacientes o sicotrópicas, tipificada en el inciso 3 del mismo artículo ${ }^{54}$. Pero, quien se apresta a conducir y se niega a someterse a las pruebas de detección, no comete el delito del artículo 195 bis inciso $1^{\circ}$.

Del ámbito típico se encuentran excluidos, asimismo, los pasajeros. Esto, sin perjuicio de la posibilidad de ser sometidos igualmente a las pruebas de detección, por ejemplo, en caso de duda respecto de quién conducía ${ }^{55}$.

Dentro de las actividades mencionadas en el artículo 110 inciso 2, cabe excluir, por último, todas aquellas que no puedan considerarse en el caso concreto, dentro de la definición de conductor recién reproducida.

\section{EL TIPO PENAL DEL ARTíCULO 195 BIS INCISO SEGUNDO}

\section{Descripción general.}

Este inciso contiene la descripción del siguiente comportamiento delictivo: "En caso de accidentes que produzcan lesiones de las comprendidas en el número $1^{\circ}$ del artículo 397 del Código Penal o la muerte de alguna persona, la negativa injustificada del conductor que hubiese intervenido en ellos a someterse a las pruebas respiratorias evidenciales [sic] o a los exámenes cientificos señalados en el artículo 183 de esta ley para determinar la dosificación de alcohol en la sangre o la presencia de drogas estupefacientes o sicotrópicas, o la realización de cualquier maniobra que altere sus resultados, o la dilación de su práctica con ese mismo efecto [...]"

Hacemos a continuación referencia a los elementos objetivos, al igual que en el caso precedente.

\section{Conductas típicas.}

La primera de las conductas descritas consiste en "la negativa injustificada", y a su respecto resulta aplicable lo ya dicho al comentar el tipo establecido en el inciso $1^{\circ}$. Lo que varía es la referencia específica, pues aquí

${ }^{54}$ La disposición establece: "En el caso que la persona se apreste a conducir bajo la influencia del alcohol, en estado de ebriedad o bajo la influencia de sustancias estupefacientes o sicotrópicas, el juez aplicará la sanción indicada en el artículo 193 ó 196, disminuida o en grado de tentativa, según corresponda".

${ }^{55}$ Por ejemplo, Carabineros se apersona en el lugar en que un automóvil se ha estrellado contra un árbol. En su interior venían tres sujetos, y al ser requeridos se niegan a la práctica de la prueba respiratoria. Sólo cabría sostener la autoría por parte del conductor, cuando sea finalmente determinado. 
el sujeto activo rehúsa someterse a las pruebas respiratorias que constituyan evidencia o a los exámenes científicos señalados en el artículo $183 \mathrm{LT}$. En este caso, a diferencia de lo que ocurre con el inciso $1^{\circ}$ del artículo 195 bis, el reenvío se efectúa a una disposición que regula tanto pruebas, aplicables por Carabineros, como exámenes científicos propiamente dichos.

Subsiste la duda respecto de quién está autorizado para requerir del conductor que se someta a un examen de alcoholemia. También, debe hacerse notar que la remisión al artículo 183, en lo que dice relación con "exámenes científicos", no es aplicable tratándose de la detección de sustancias estupefacientes o sicotrópicas, dado que tal disposición sólo regula el examen científico apto para determinar la dosificación del alcohol en la sangre o en el organismo. Es decir, estrictamente, la alcoholemia.

Se señalan dos comportamientos más. Uno es "la realización de cualquier maniobra que altere sus resultados" (es decir, los de las pruebas respiratorias que constituyan evidencia o a los exámenes científicos señalados en el artículo 183 de esta ley para determinar la dosificación de alcohol en la sangre o la presencia de drogas estupefacientes o sicotrópicas). El otro es "la dilación de su práctica con ese mismo efecto".

Con el empleo de esta técnica de descripción se evitan desde ya ciertos aspectos problemáticos que podrían haberse presentado en materia de tipicidad $^{56}$. En consecuencia, pierde bastante importancia el problema de las que cabría denominar "negativas implícitas". Porque éstas, muchas veces, podrán quedar subsumidas en los otros comportamientos descritos en este inciso, ya que generalmente consistirán en la realización de maniobras tendientes a alterar los resultados de las pruebas (no espirar íntegramente, o intentar introducir sólo parte del aliento, liberando el resto al aire, etc.), o dilatar la práctica de las mismas (hacerse el dormido, simular no poder operar el aparato, etc.). En todo caso, no se comprende por qué los comportamientos típicos adicionales sólo fueron previstos para la situación del inciso $2^{\circ}$.

Puede apreciarse que estamos ante un tipo de hipótesis alternativas, de manera que la ejecución de cualquiera de las conductas establecidas en la ley basta para su realización ${ }^{57}$. Por otra parte, esto significa que la ejecución de más de una de ellas no obsta para que tal pluralidad continúe

${ }^{56}$ FernÁNdez Bautista, Silvia, cit. (n. 36), pp. 200-201, refiere cómo en el caso del delito análogo previsto en el Código Penal español, que no prevé hipótesis adicionales a la de la negativa propiamente dicha, en ocasiones se ha equiparado a una negativa típica la realización voluntariamente defectuosa de la prueba de detección de alcohol por espiración de aire. Lo que, coloquialmente, en ambos países, entendemos como "soplar mal".

${ }^{57}$ Mir Puig, Santiago, cit. (n. 32), p. 236. 
considerándose como un único delito, debiendo descartarse su apreciación como un concurso real de delitos ${ }^{58}$.

\section{Sujetos.}

Se trata, nuevamente, del conductor, definido por el artículo $2 \mathrm{~N}^{\circ} 9$ LT. Pero, además, dicho conductor debe haber intervenido en un hecho de tránsito ("accidente") productor de lesiones graves gravísimas o la muerte de alguna persona.

Debe quedar excluido, por el tenor literal del artículo 195 bis, el peatón que haya tenido participación en un hecho de tránsito del que resulten lesionados o muertos, mencionado en el artículo 183 inciso final. Ello, no obstante que deba ser requerido para someterse a las referidas pruebas.

\section{Las situaciones tipicas del inciso segundo.}

De acuerdo con el inciso $2^{\circ}$ del artículo 195 bis, se conmina con mayor pena el que la negativa propiamente dicha, $u$ otra de las conductas que alternativamente indica la ley, se cometan "en caso de accidentes que produzcan lesiones de las comprendidas en el número $1^{\circ}$ del artículo 397 del Código Penal o la muerte de alguna persona".

El término "accidentes" no puede, lógicamente, significar una restricción de la hipótesis delictiva al ámbito de situaciones fortuitas, a la manera del artículo $10 \mathrm{~N}^{\circ} 8 \mathrm{CP}$. Los hechos puramente accidentales no quedan excluidos, pero a éstos deben sumarse todos los demás, dolosos y culposos, en que tales resultados se produzcan. Por eso resulta preferible la denominación más general de "hechos de tránsito", capaz de abarcar todas las posibilidades indicadas.

Como lo determinante para la aplicación del inciso $2^{\circ}$ es la ocurrencia del hecho material que acarrea ciertas consecuencias, y no el obrar doloso o culposo de quienes han intervenido en él, parece acertada la referencia estrictamente material a la producción de la "muerte" de alguna persona. Tomando por base esta reflexión es que, siempre en un plano fáctico, el otro resultado señalado por la ley debiera entenderse como la producción de demencia, inutilidad para el trabajo, impotencia, impedimento de algún miembro importante o notable deformidad. En la hipótesis del artículo

\footnotetext{
${ }^{58}$ Jescheck, Hans-Heinrich - Weigend, Thomas, Tratado de derecho penal. Parte general ( 5 a edición, traducción castellana de Miguel Olmedo Cardenete, Granada, Comares, 2002), p. 285. Cfr. Cury URZúa, Enrique, Derecho penal. Parte general (6a edición, Santiago, Ediciones Universidad Católica de Chile, 2005), p. 653; Politoff Lifschitz, Sergio - Matus Acuña, Jean Pierre - Ramírez Guzmán, María Cecilia, Lecciones de derecho penal chileno. Parte general (Santiago, Editorial Jurídica de Chile, 2004), pp. 451-452.
} 
195 inciso $2^{\circ}$ el hecho de tránsito es causa de determinados resultados materiales; la referencia al artículo $397 \mathrm{~N}^{\circ} 1$ debe considerarse sólo una manera abreviada de remitirse a ellos.

En cuanto a la naturaleza de esta referencia hecha por la disposición legal, se hace necesaria una reflexión. A nuestro juicio, estamos ante un elemento objetivo del tipo, que consiste en lo que la doctrina tradicionalmente ha denominado "ciertas circunstancias especiales que deben rodear la conducta", tratándose en este caso de una indicación respecto de un tiempo determinado en que ella debe ejecutarse ${ }^{59}$.

Dicho período de tiempo se inicia inmediatamente con posterioridad a la producción de un hecho de tránsito (ya sea accidental, culposo o doloso) y de la producción de los resultados derivados de éste, señalados en la ley.

Por otra parte, la extensión del mismo período no está bien determinada. Pero, para que pueda tener algún sentido tal exigencia típica, debe relacionarse con el tiempo en que aún resulte útil la práctica de las pruebas o exámenes respectivos. Esto es, generalmente, unas cuantas horas.

Como elemento típico, la circunstancia especial de tiempo, expresada por el inciso $2^{\circ}$, debe quedar cubierta por el dolo del agente.

\section{LA PARTE SUBJETIVA DE LOS TIPOS EXAMINADOS}

El artículo 195 bis LT. establece dos tipos dolosos. Pese a que, en principio, su comisión no está limitada al actuar con dolo directo, no resulta fácil concebir situaciones en que la negativa se esté prestando con dolo eventual.

El conocimiento del sujeto activo debe abarcar la existencia de un requerimiento por quien, de acuerdo con la información manejada al nivel del profano, está autorizado a efectuar. También, que se está manifestando una negativa, en cualquiera de las formas antes indicadas o alternativamente, en el caso del inciso $2^{\circ}$, que se están realizando maniobras tendientes a alterar los resultados de las pruebas o se está dilatando la práctica de las mismas.

A nuestro juicio, la singular agravación dispuesta por el inciso $2^{\circ}$, hace indispensable insistir en que es necesario el conocimiento por parte del autor de la negativa, de que se ha intervenido en un hecho de tránsito del que han resultado lesiones graves gravísimas o la muerte de alguna persona.

Se prevén ciertas complicaciones aplicativas vinculadas a la temática del error. Por ejemplo, ya es complejo en el propio lugar de los hechos, determinar la gravedad de una lesión, antes de practicar la prueba de detección.

${ }^{59}$ Novoa Monreal, Eduardo, Curso de derecho penal chileno (Santiago, Editorial Jurídica de Chile, 1960), I, pp. 313-314; Cury UrZÚA, Enrique, cit. (n. 58), p. 291. 


\section{Conclusiones}

Del examen de los tipos penales contenidos en la disposición legal recientemente incorporada como artículo 195 bis LT y su contexto, se desprenden las siguientes conclusiones.

$1^{\circ}$ Como apreciación general puede sostenerse que el estado en que se encuentra la legislación de tránsito no es el mejor. Ha sido tal la seguidilla de modificaciones, sin una adecuada visión de conjunto, que resulta difícil, ahora desde la perspectiva penal, tener un panorama claro respecto de los límites que se trazan al establecer tipos como los examinados. Esto resulta patente, en el ámbito de la regulación de las pruebas y exámenes de detección de alcohol y drogas.

$2^{\circ}$ Seguramente podrá compartirse que la Ley $N^{\circ} 20.770$ es un ejemplo más del excesivo recurso a la herramienta penal. En verdad, al haber tenido la oportunidad de examinar la evolución legislativa en la materia, y de observar la progresiva criminalización de comportamientos que antes quedaban en el campo del derecho administrativo sancionador, quedan serias dudas respecto de que esta inclinación sea el camino correcto. Al menos, no parece que haya existido un intento de maximizar el rendimiento del papel de la Administración en la materia, antes de seguir este camino tan cuestionado.

$3^{\circ}$ Es verdad que el régimen de presunciones establecido desde antiguo para inducir a los conductores a someterse a las pruebas o exámenes de detección, cuya última expresión desapareció con la derogación del artículo 183 inciso $5^{\circ}$, está desacreditado. Sin embargo, la sustitución de aquel mecanismo por uno basado en la amenaza penal a quien manifiesta su negativa, se encuentra con problemas tanto o más graves. Y es previsible que en Chile se produzca un debate respecto de la legitimidad de este delito, que no se centrará solo en el ámbito de las garantías penales, sino también en las procesales y, en definitiva, en su constitucionalidad. Quizás no se pierda nada sino, por el contrario, se gane al anticipar que en España el debate se produjo y está resuelto, al menos oficialmente, porque el Tribunal Constitucional de aquel país resolvió que no existe, por obra del legislador, infracción al derecho por no declarar contra uno mismo y no confesarse culpable, ni a la presunción de inocencia, entre otros. Puede ser nuestra misión renovar la discusión y ofrecer nuevos puntos de vista sobre la vigencia de los derechos fundamentales frente a la persecución penal.

$4^{\circ}$ Más allá de lo legítimo que resulte articular mecanismos que presionen al imputado a la realización de pruebas o exámenes de las que fluya información útil para incriminarlo, si se quiso normar en favor de la regularidad de los procedimientos policiales o médico-legales de detección 
de sustancias que puedan afectar la conducción, nuestra opinión es que el mecanismo idóneo para ello es el derecho administrativo sancionador. En consecuencia, este comportamiento debiera integrar el ámbito de las infracciones listadas en la Ley del Tránsito.

\section{BIBLIOGRAFÍA}

Alonso Rimo, Alberto, El delito de negativa a someterse a las pruebas de alcoholemia $o$ de detección drogas tóxicas desde la perspectiva de la reforma penal de 2007, en Vidales Rodríguez, Caty - Mera Redondo, Antonio (coordinadores), Seguridad vial (Especial referencia a la reforma operada en el Código Penal mediante la Ley Orgánica 15/2007, de 30 de noviembre) (Valencia, Tirant lo Blanch, 2008).

Cury Urzúa, Enrique, Derecho penal. Parte general (6a edición, Santiago, Ediciones Universidad Católica de Chile, 2005).

Fernández BAUtista, Silvia, El delito de negativa a la realización de las pruebas de alcoholemia, en Mir PUIG - Corcoy BIDASOlo (directores), Seguridad vial y derecho penal (Valencia, Tirant lo Blanch, 2008).

Gallego Soler, Ignacio, El nuevo delito de conducción bajo los efectos del alcohol y las drogas (artículo 379.2 CP), en Mir PUIG - CorCOY BidAsOlo (directores), Seguridad vial y derecho penal (Valencia, Tirant lo Blanch, 2008).

Gutiérrez Rodríguez, María - García del Blanco, Victoria - Martín Lorenzo, María - Sanz-Díez de Ulzurrun Lluch, Marina, Protección penal de la seguridad vial (Valencia, Tirant lo Blanch, 2009).

Hernández Basualto, Héctor, Alcances del delito de desacato en el contexto de la Ley de Violencia Intrafamiliar, en Defensoría Penal Pública (editor), Informes en derecho. Doctrina procesal penal 2010 (Santiago, Editorial Atenas, 2011).

Jescheck, Hans-Heinrich - Weigend, Thomas, Tratado de derecho penal. Parte general ( $5^{\text {a }}$ edición, traducción castellana de Miguel Olmedo Cardenete, Granada, Comares, 2002).

Mir Puig, Santiago, Derecho penal. Parte general (9a edición, Barcelona, Reppertor, 2011).

Miró Llinares, Fernando, Artículo 383, en Cobo del Rosal (director), Comentarios al Código Penal. Segunda época (Madrid, Cesej, 2008), XI.

Montaner Fernández, Raquel, Delitos contra la seguridad vial, en Silva Sánchez (director), Lecciones de derecho penal. Parte especial ( $3^{\text {a }}$ edición, Barcelona, Atelier, 2011).

Novoa Monreal, Eduardo, Curso de derecho penal chileno (Santiago, Editorial Jurídica de Chile, 1960), I.

Politoff Lifschitz, Sergio - Matus Acuña, Jean Pierre - Ramírez GuZmán, María Cecilia, Lecciones de derecho penal chileno. Parte general (Santiago, Editorial Jurídica de Chile, 2004).

Queralt Jiménez, Joan, Derecho penal español. Parte especial (6 $6^{a}$ edición, Barcelona, Atelier, 2010).

Silva Silva, Hernán, El delito de manejar en estado de ebriedad (2ª edición, Santiago, Editorial Jurídica de Chile, 2009). 
